\title{
AVALIAÇAO DE HÍBRIDOS DE COQUEIRO (Cocos nucifera L.) PARA PRODUÇÃo DE FRUTOS E DE ALBÚMEN SÓLIDO FRESCO'
}

\author{
PAULO MANOEL PONTES LINS², JOÃO TOMÉ DE FARIAS NETO³, ANTÔNIO AGOSTINHO MÜLLER 3
}

\begin{abstract}
RESUMO - Avaliou-se o desempenho de seis híbridos de coqueiro para produção de frutos e de albúmen sólido fresco no Município de Moju, PA. Os híbridos avaliados foram: PB 121 (Anão-amarelo da Malásia x Gigante Oeste Africano); PB 111 (Anão-vermelho de Camarões x Gigante Oeste Africano); PB 141 (Anão-verde do Brasil x Gigante Oeste Africano); PB 123 (Anão-amarelo da Malásia x Gigante de Renel); PB 132 (Anão-vermelho da Malásia x Gigante da Polinésia) e PB 113 (Anão-vermelho de Camarões x Gigante de Renel), em delineamento em blocos casualizados com seis repetições. Verificou-se, pela análise de variância, diferença significativa para tratamentos, resultante da heterogeneidade do material genético estudado. As fontes de variação ano e a interação anos x tratamentos foram também altamente significativas, evidenciando que o comportamento dos híbridos foi induzido por aquelas fontes de variação. Considerando o desempenho dos híbridos no período de 9 anos de avaliação para produção de frutos e de albúmen fresco, pode-se recomendar para plantio os híbridos PB 111, PB 113, PB 141 nas condições do Estado do Pará, com vistas a atender às indústrias (albúmen sólido), quanto à venda de cocos "in natura" para consumo de água.
\end{abstract}

Termos para indexação: seleção, desempenho, melhoramento genético, híbridos de coqueiro.

\section{PERFORMANCE OF HYBRIDS OF COCONUT PALM FOR PRODUCTION OF FRUITS AND SOLID FRESH ALBUMEN}

\begin{abstract}
The performance of six hybrids of coconut palm were evaluated for fruit and solid fresh albumen production in Moju, State of Pará. The evaluated hybrids were: PB 121 (Dwarf Yellow of Malaysia x West African Giant); PB 111 (Dwarf Red of Cameron x West Afican Giant); PB 141 (Dwarf Green of Brazil x West Aficam Giant); PB 123 (Dwarf Yellow of Malaysia x Renel's Giant); PB 132 (Red Dwarf of Malaysia x (Giant from Polynesia); PB 113 (Dwarf Red of Cameron x Renel's Giant) in hazard blocks and six repetitions. It was verified through variance analysis, significancy difference between treatments, as result of the heterogeneity of the studied genetic material. The sources of variation year and the interaction years $\mathrm{x}$ treatments showed also highly significant, evidencing that the behavior of the hybrids was induced for those sources of variation. Considering the performance of the hybrids in the period of nine years of evaluation for fruit and fresh solid albumen production, the hybrids PB 111 , PB 113 and PB 141 may be recommended for planting in Pará State.
\end{abstract}

Index terms: selection, performance, genetic breeding, coconut palms hybrids

\section{INTRODUÇÃO}

A produção brasileira de coco é de fundamental importância econômica e social para a Região Nordeste, onde se encontra a maior produção de coco do País. Em 2001, com uma produção de 941,793 milhões de frutos, essa região respondeu por $70,67 \%$ da produção nacional de coco. O Estado da Bahia é o principal produtor, com uma área colhida de 80.342 ha e produção de 424.444 milhões de frutos, seguido dos Estados do Ceará e do Pará, esse último com 20.334 ha de área colhida e produção de 196.993 milhões de frutos (Agrianual, 2003).

A produtividade média brasileira de coco é baixa, na ordem de 20 a 30 frutos/planta/ano (Aragão et al., 1997) e a produção não tem sido suficiente para atender a demanda do mercado interno, o que tem resultado, como conseqüência, em importações de volumes expressivos de coco seco e semi-industrializado e, até mesmo, de coco verde para água (Agrianual, 2003). No Estado do Pará a cultura do coqueiro tem se caracterizado pela baixa produtividade devido principalmente à implantação da cultura ocorrer com sementes de origem genética desconhecida, não existindo normalmente campos de matrizes de coqueiro, estabelecidos segundo os padrões técnicos para produção de sementes certificadas do próprio coqueiro anão ou do coqueiro híbrido, além do manejo inadequado da cultura.

Uma das estratégias que os melhoristas passaram a adotar, no sentido de aumentar a produtividade de coco e resolver outros problemas da cultura, envolve a avaliação de híbridos entre as variedades Anão x Gigante, visto que, em relatos da literatura observase que a manifestação da heterose em coqueiro ocorre para a produção de frutos, precocidade, resistência a pragas e doenças, número de folhas, circunferência do coleto (Santos et al., 1982), porcentagem de germinação (Faria et al., 2002). De acordo com Ferraz et al. (1987), muitas empresas brasileiras optaram pela importação de sementes híbridas da Costa do Marfim.

Considerando-se, entre outras, as variações climáticas, entre a região de origem dos híbridos e as reinantes no Estado do Pará, onde a cultura do coqueiro se encontra em franca expansão, há necessidade de se buscar informações experimentais que permitam identificar os genótipos mais promissores para serem recomendados aos produtores, contribuindo, dessa forma, para a melhoria do sistema de produção da cultura.

Este trabalho foi conduzido com a finalidade de avaliar o desempenho de seis híbridos de coqueiro para produção de frutos e de albúmen fresco, com vista à recomendação de novos cultivares para plantio.

\section{MATERIAL EMÉTODOS}

O experimento foi instalado na Fazenda Socôco, localizada no Município de Moju, PA, situada a $02^{\circ} 07^{\prime} 00^{\prime \prime}$ de latitude Sul e $48^{\circ}$ de longitude Oeste de Greenwich, distando $100 \mathrm{~km}$ da cidade de Belém. A altitude é de 30 metros, com pluviosidade média anual de $2.695 \mathrm{~mm}$ e temperatura média de $27^{\circ} \mathrm{C}$, umidade relativa do ar de $82 \%$ e constante iluminação solar. O solo da área experimental é um Latossolo Amarelo Distrófico, textura argilo arenosa e relevo suave. Não foi utilizada irrigação artificial. Os resultados da análise do solo, coletado na profundidade de 0 a $20 \mathrm{~cm}$ e de 20 a $40 \mathrm{~cm}$, são apresentados na Tabela 1.

\footnotetext{
${ }^{1}$ (Trabalho 059/2003). Recebido: 31/03/2003. Aceito para publicação: 24/10/2003. Realizado através da parceria da Embrapa Amazônia Oriental e a empresa Socôco S.A. Agroindústria da Amazônia.

${ }^{2}$ Eng. Agr. Gerente de Pesquisa e Desenvolvimento da empresa Socôco S.A Agroindústrias da Amazônia. Rod. PA 252, km 38, CEP 68450-000. C. P. 15, Moju,PA.pmplins@uol.com.br.

${ }^{3}$ Pesquisadores da Embrapa Amazônia Oriental. Trav. Dr. Enéas Pinheiro s/n. CEP 66095-100, C. P. 48, e-mail: tome@cpatu.embrapa.br; amuller@cpatu.embrapa.br.
} 
TABELA 1 - Características químicas do solo da área experimental em duas profundidades de coleta. Fazenda Socôco, Moju, PA. 1984.

\begin{tabular}{ccccccccccc}
\hline Prof. & $\mathrm{pH}$ & $\mathrm{MO}$ & $\mathrm{P}$ & $\mathrm{K}$ & $\mathrm{Ca}+\mathrm{Mg}$ & $\mathrm{Al}$ & $\mathrm{H}$ & $\mathrm{T}$ & $\mathrm{V}$ & $\mathrm{m}$ \\
\hline $\mathrm{cm}$ & $\mathrm{CaCl}_{2}$ & $\mathrm{~g} / \mathrm{dm}^{3}$ & $\mathrm{mg} / \mathrm{dm}^{3}$ & & & $\mathrm{mmolc} / \mathrm{dm}^{3}$ & & $\%$ \\
\hline 00 a 20 & 3,9 & 18 & 8 & 1,4 & 10,0 & 8,0 & 34,0 & 6,0 & 25 & 41 \\
20 a 40 & 4,0 & 19 & 4 & 0,8 & 7,0 & 8,0 & 28,0 & 10,0 & 22 & 51 \\
\hline
\end{tabular}

O plantio dos híbridos ocorreu no ano de 1984 e o início da avaliação ocorreu de 1989 até 1997 . O delineamento experimental utilizado foi o de blocos casualizados, com seis repetições, sendo as parcelas experimentais representadas por 30 plantas, no espaçamento de $8,5 \mathrm{~m} \mathrm{x}$ $8,5 \mathrm{~m}$, em arranjo triangular equilátero. As adubações foram realizadas anualmente, de acordo com a diagnose foliar. Os tratos culturais como capinas foram realizados bimestralmente e a colheita dos frutos ocorreu de 2 em 2 meses.

Os híbridos avaliados foram: PB 121 (Anão-amarelo da Malásia x Gigante Oeste Africano); PB 111 (Anão-vermelho de Camarões x Gigante Oeste Africano); PB 141 (Anão- verde do Brasil x Gigante Oeste Africano); PB 123 (Anão-amarelo da Malásia x Gigante de Renel); PB 132 (Anão-vermelho da Malásia x Gigante da Polinésia) e PB 113 (Anãovermelho de Camarões x Gigante de Renel), todos fornecidos pelo Institut de Recherches pour les Huiles et Oléagineux - IRHO, França.

Embora tenham sido tomados dados de vários caracteres agronômicos, somente foram analisados o número de frutos/planta e a produção de albúmen sólido fresco. Os dados de número de frutos/planta foram transformados para $\sqrt{x}$. Realizou-se a análise de variância para cada ano, para estimar a relação entre o maior e o menor quadrado médio do resíduo, para cada ano, visando verificar se haveria a necessidade de ajustes de graus de liberdade das fontes de variação, para posterior análise de variância conjunta de ambientes. Consideraram-se os efeitos de tratamentos como fixo e de ano como aleatório As análises de variância foram efetuadas através do programa GENES (Cruz, 2001).

O modelo matemático empregado foi: $Y i j k=m+G i+A j+B / A j k$

+ Gaij + Eijk, sendo: $\bar{Y}_{i j k}$ valor fenotípico do caráter Y medido no material genético $\mathrm{i}$, no ambiente $\mathrm{j} ; \mathrm{m}=$ média geral paramétrica dos dados em estudo; $\mathrm{Gi}=$ efeito do i-ésimo genótipo; $\mathrm{Aj}=$ efeito do j-ésimo ambiente experimental; $\mathrm{B} / \mathrm{A}_{\mathrm{ik}=}$ efeito de blocos dentro de ambiente; $\mathrm{Gaij}=$ efeito da interação do i-ésimo genótipo com o j-ésimo ambiente; $\mathrm{E}_{\mathrm{ijk}=}$ erro médio associado à observação Yijk.

\section{RESULTADOS E DISCUSSÃO}

Na Tabela 2, apresentam-se os resultados da análise de variância dos caracteres número de frutos/planta e produtividade de albúmen sólido fresco. Foram detectadas diferenças significativas para tratamentos, fato que reflete a heterogeneidade do material genético estudado, indicando a possibilidade de identificação de materiais promissores. Foi detectado efeito significativo para as fontes de variação ano e para a interação anos x tratamentos, o que mostra comportamento diferenciado dos híbridos nas diferentes idades e evidencia o efeito de periodicidade nesses caracteres. Tal fato significa também que as plantas a serem submetidas à seleção tenham suas produções avaliadas mediante observações repetidas, para que se obtenha resposta mais próxima do seu valor genotípico. Em coqueiro, segundo Fremond et al. (1975), deve ser observado, com rigor, durante, no mínimo, 3 anos de produção, a fim de que seja selecionado um genótipo superior. Foi obtido nível ótimo de precisão experimental, conforme indicação fornecida pelos baixos valores dos coeficientes de variação experimental.

A relação entre o maior e o menor quadrado médio dos resíduos das análises de variância por ano foi de 5,56 e 5,75, para número de frutos/planta e produtividade de albúmen sólido fresco, respectivamente, indicativo que a precisão experimental entre os experimentos não foram discrepantes, por serem menores que sete, o que, segundo Gomes (1991), permite a realização da análise conjunta sem ajuste dos graus de liberdade.
TABELA 2 - Análise de variância conjunta com os valores e significâncias dos quadrados médios dos caracteres número de frutos/planta e produtividade de albúmen fresco (PAF), envolvendo híbridos de coqueiro avaliados em 9 anos. Fazenda Socôco, Moju, PA. 2002.

\begin{tabular}{lccc}
\hline \multirow{2}{*}{$\begin{array}{c}\text { Fontes de } \\
\text { variação }\end{array}$} & G.L. & \multicolumn{2}{c}{ Quadrados Médios } \\
\cline { 3 - 4 } & & $\mathrm{N}^{\circ}$ de frutos/planta & $\mathrm{PAF}(\mathrm{kg} / \mathrm{ha})$ \\
\hline Blocos/Ano & 45 & 0,3133 & 527152,678 \\
Ano (A) & 8 & $46,1515^{* *}$ & $7522176,464^{* *}$ \\
Tratamentos (T) & 5 & $3,0566^{* *}$ & $59696335,806^{* *}$ \\
A x T & 40 & $0,4328^{* *}$ & $553211,262^{* *}$ \\
Resíduo médio & 225 & 0,1449 & 201643,817 \\
\hline CV (\%) & & 9,04 & 8,57 \\
Média & & 83 & 5241 \\
\hline
\end{tabular}

** : significativo a $1 \%$ de probabilidade, pelo teste $\mathrm{F}$.

Na Tabela 3, encontram-se os valores médios obtidos pelos híbridos para os caracteres. Verifica-se que o híbrido PB 111 apresentou a maior produção de frutos/planta, não diferindo estatisticamente dos híbridos PB 141, PB 113, PB 121 e PB 123. Quanto à produtividade de albúmen sólido fresco, o melhor desempenho foi observado pelo híbrido PB 113, seguido do PB 111 e PB 141, não havendo diferença significativa entre eles. O resultado dos mesmos híbridos, por apresentarem as maiores produções de albúmen, estar entre aqueles com maior número de frutos/ planta já era esperado, haja vista que o valor da correlação fenotípica entre os caracteres foi alto $(0,94)$. Vale ressaltar que o fato dos três híbridos não apresentarem diferenças significativas entre si sugere a possibilidade do plantio dos três de maneira simultânea, fato que promoverá maior diversidade de genótipos na área de cultivo, evitando, desse modo, maior vulnerabilidade genética às doenças, às pragas e às condições edafo-climáticas adversas. $\mathrm{O}$ menor valor de número de frutos/planta foi observado no PB 132. Os menores valores de produtividade de albúmen sólido fresco foram apresentados pelos híbridos PB 123 (4.822,4 kg/ha), PB 132 (4.952,7 kg/ha) e PB 121 (5.018,1 $\mathrm{kg} / \mathrm{ha}$ ), com valores inferiores à média geral dos anos, que foi de 5.243,6 $\mathrm{kg} / \mathrm{ha}$.

TABELA 3 - Valores médios para número de frutos/planta e produtividade de albúmen sólido fresco $(\mathrm{kg} / \mathrm{ha})$, obtidos por seis híbridos em 9 anos de avaliação. Fazenda Socôco, Moju, PA. 2002.

\begin{tabular}{ccc}
\hline Híbridos & $\begin{array}{c}\text { Número de } \\
\text { frutos/planta }\end{array}$ & $\begin{array}{c}\text { Produtividade de albúmen } \\
\text { sólido fresco }\end{array}$ \\
\hline PB121 & $83,5 \mathrm{ab}$ & $5.018,1 \mathrm{~b}$ \\
PB 111 & $90,4 \mathrm{a}$ & $5.557,7 \mathrm{ab}$ \\
PB 141 & $86 \mathrm{ab}$ & $5.338,7 \mathrm{ab}$ \\
PB 123 & $80,7 \mathrm{ab}$ & $4.822,4 \mathrm{~b}$ \\
PB 132 & $78,6 \mathrm{~b}$ & $4.952,7 \mathrm{~b}$ \\
PB 113 & $85,1 \mathrm{ab}$ & $5.771,9 \mathrm{a}$ \\
\hline Média geral & 84,2 & $5.243,6$ \\
Coeficiente de & & \\
correlação & 0,94 &
\end{tabular}

${ }^{1}$ Médias seguidas pela mesma letra não diferem entre si pelo teste de Tukey a $5 \%$ de probabilidade

Observa-se que o efeito da periodicidade foi pronunciado, tendo o número de frutos/planta variado de 74, em 1996, a 119, em 1997 (Figura 1), enquanto a produtividade média de albúmen fresco variou de $4.263 \mathrm{~kg} / \mathrm{ha}$ a $7.226 \mathrm{~kg} /$ ha no mesmo período (Figura 2). 
Número de frutos por planta

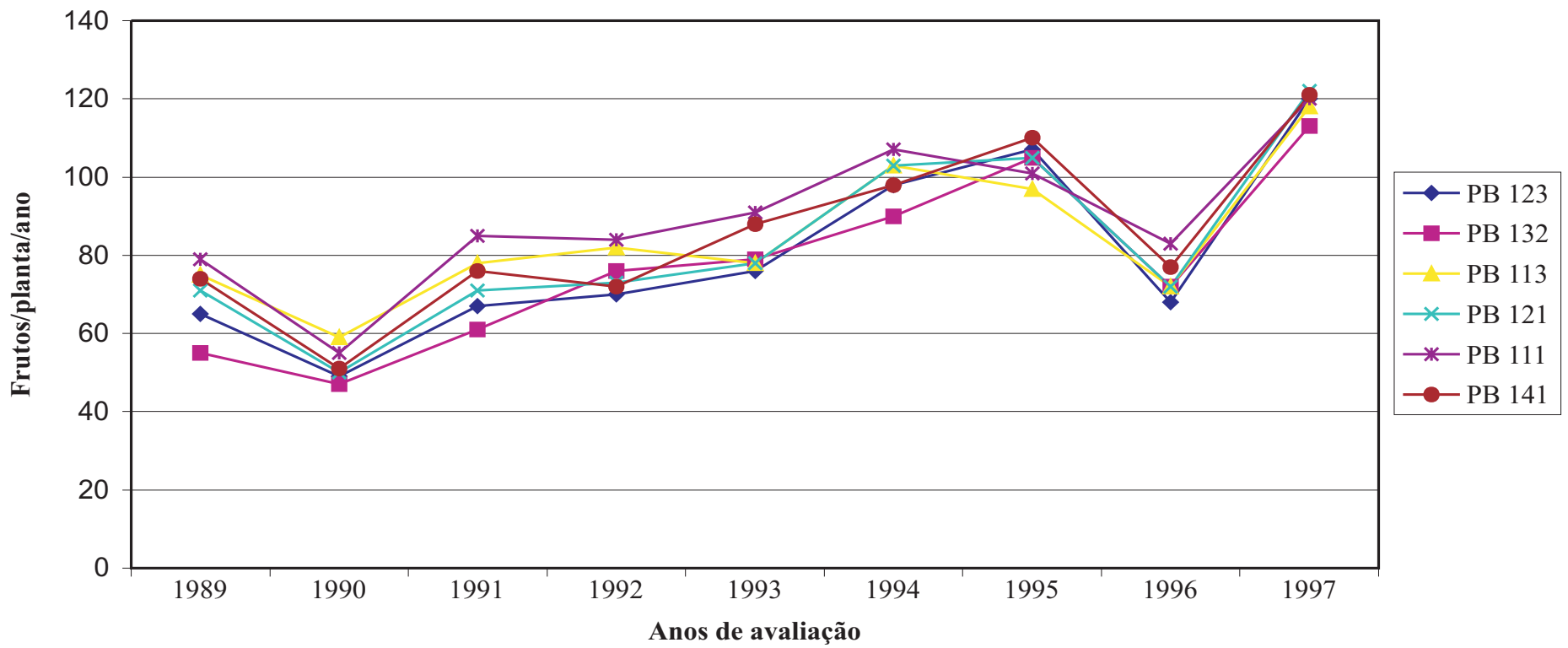

FIGURA 1 - Número de frutos/planta/ano de híbridos de coqueiro. Fazenda Socôco, Moju, PA. 2002

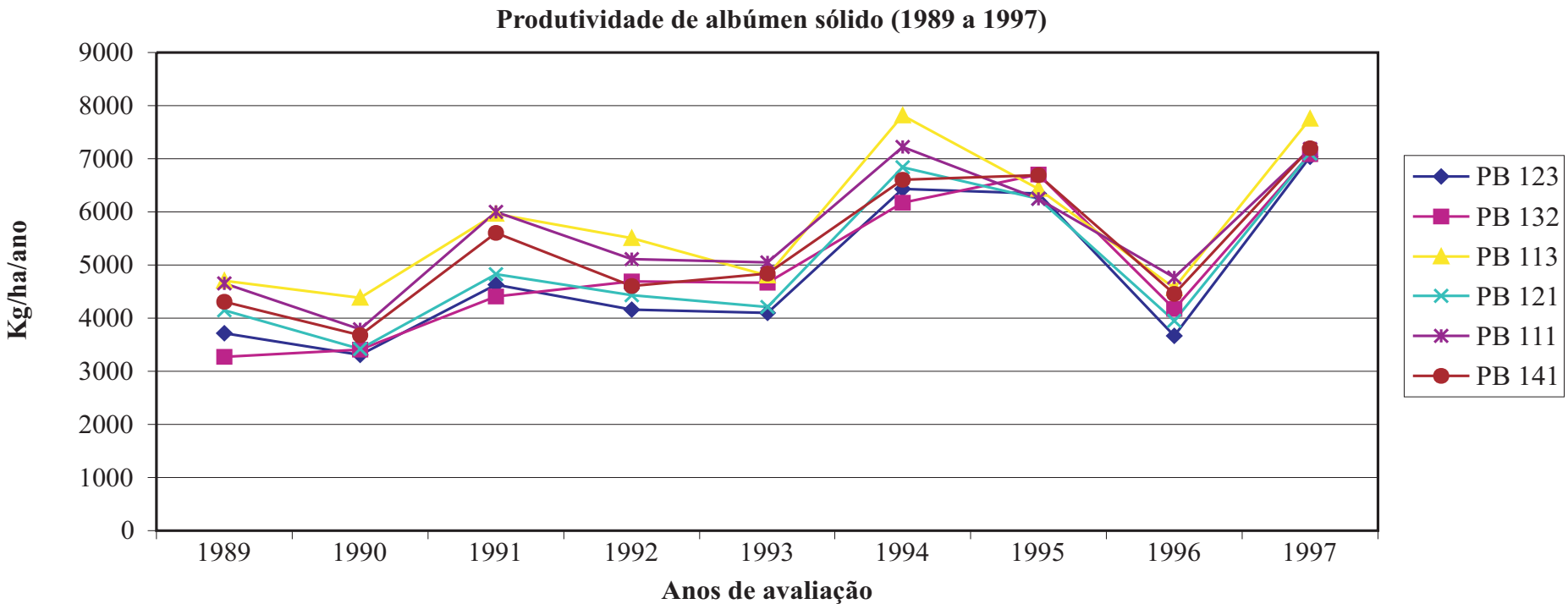

FIGURA 2 - Produtividade de albúmen fresco/ano de híbridos de coqueiro. Fazenda Socôco, Moju, PA. 2002

\section{CONCLUSÕES}

1) Considerando o desempenho dos híbridos no período de 9 anos de avaliação para os caracteres número de frutos/planta e produtividade de albúmen sólido fresco, recomenda-se os híbridos PB 111, PB 113 e PB 141 para plantio no Estado do Pará.

2) Recomenda-se o plantio dos híbridos superiores de maneira conjunta numa mesma área de modo a promover maior diversidade de genótipos na área de cultivo, evitando, maior vulnerabilidade genética às doenças, às pragas e às condições edafo-climáticas adversas

\section{REFERÊNCIAS BIBLIOGRÁFICAS}

AGRIANUAL. anuário Estatístico da Agricultura Brasileira. São Paulo: FNP Consultoria \& Comércio, 2003.

ARAGÃO, W.M.; CASTILHO, E.L.; FERREIRA, J.M.S.; RIBEIRO, F.E.; TUPINAMBÁ, E.E.M.; FERREIRA, M.L.; WARWICK, D.R. Avaliação de híbridos intervarietais do coqueiro no tabuleiros costeiros do sul do Sergipe. Aracaju:EMBRAPA-CPAT, 1997.3p. (Pesquisa em andamento, 22)
CRUZ, C.D. Programa Genes: aplicativo computacional em genética e estatística. Viçosa, MG: UFV, 2001. 648p.

FARIAS, W.S.; GAÍVA, H.N.; PEREIRA, W.E. Comportamento de cinco genótipos de coqueiro (Cocos nucifera L.) na fase de germinação e de crescimento de mudas, sob diferentes sistemas de produção. Revista Brasileira de Fruticultura, Jaboticabal, v.24, n.2, p. 458462, 2002.

FERRAZ, L.G.B.; PEDROSA, A.C.; MELO, G.S. Avaliação do comportamento de coqueiro híbrido e cultivares nacionais. Recife/ PE:IPA, 1987. 7p. (IPA. Pesquisa em Andamento, 5).

FREMOND, Y.; TILLER, R.; LAMOTHE, M.N. La selección. In: El cocotero. 1975. P. 33-49.

GOMES, F.P. Análise de grupos de experimentos In: GOMES, F.P. (Ed.) Curso de estatística experimental. 14. ed. Piracicaba: Nobel, 1991. cap.8, p.168-197.

SANTOS, G.A.; CARPIO, C.B.; ILAGAN, M.C.; CANO, S.B.; DELACRUZ, B.V. Flowering and early performance of four IRHO coconuts hybrids in the Philippines. Oléagineux, Paris, v.37, n.12, p.571-580, 1982. 